Document downloaded from:

http://hdl.handle.net/10251/104455

This paper must be cited as:

Tampau, A.; González Martínez, MC.; Chiralt, A. (2017). Carvacrol encapsulation in starch or PCL based matrices by electrospinning. Journal of Food Engineering. 214:245-256. doi:10.1016/j.jfoodeng.2017.07.005

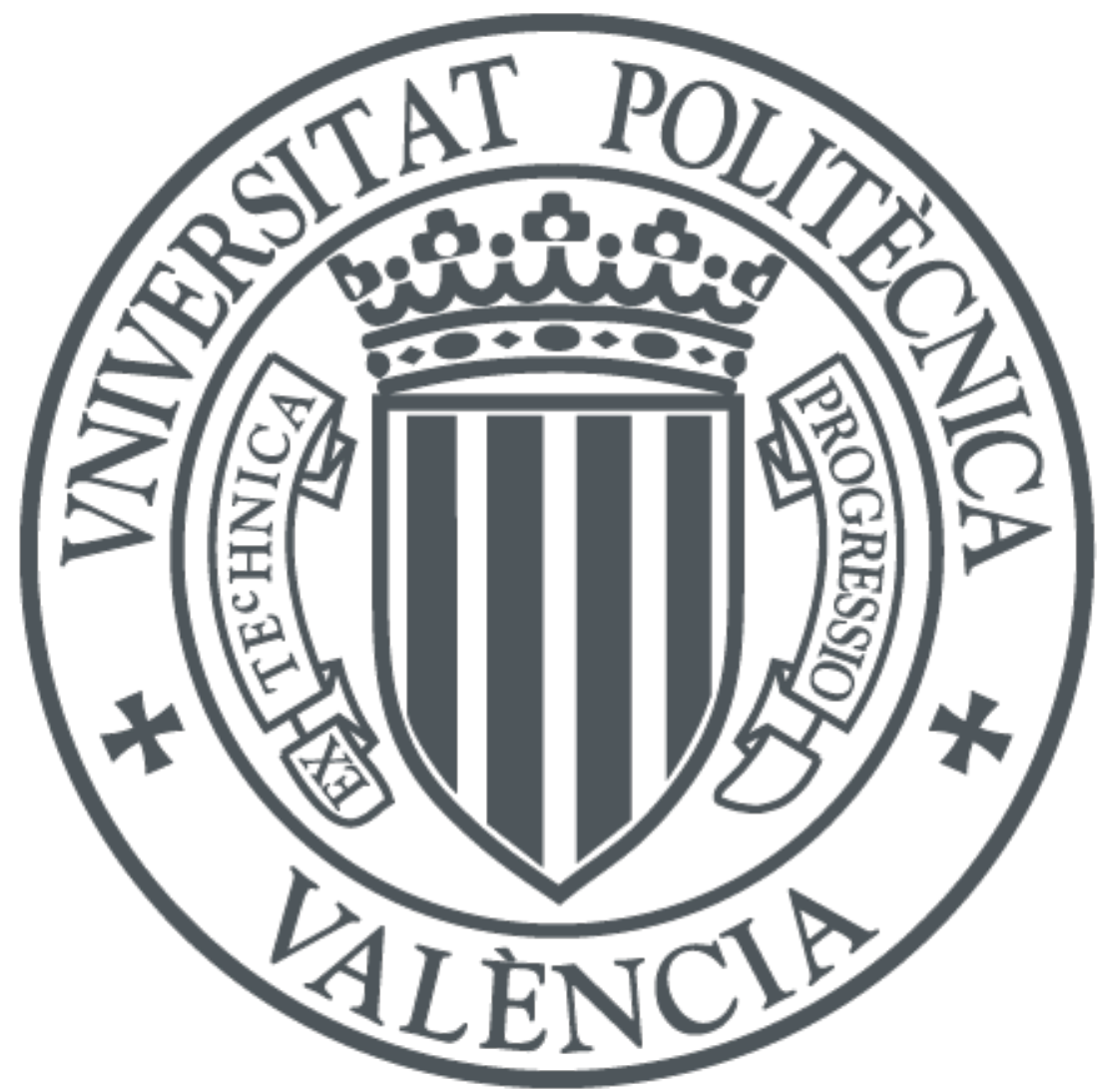

The final publication is available at

https://doi.org/10.1016/j.jfoodeng.2017.07.005

Copyright Elsevier

Additional Information 


\title{
Carvacrol encapsulation in starch or PCL based matrices by electrospinning
}

\author{
Alina Tampau ${ }^{\mathrm{a} 1}$, Chelo González-Martínez ${ }^{\mathrm{b}}$, Amparo Chiralt ${ }^{\mathrm{c}}$ \\ a,b,c Instituto Universitario de Ingeniería de Alimentos para el Desarrollo, Ciudad Politécnica de la Innovación, \\ Universitat Politécnica de Valencia, Camino de Vera, s/n, 46022 Valencia, Spain
}

\begin{abstract}
Carvacrol (CA) was encapsulated in polar (corn starch-Sodium caseinate, CS:NaCas) or non-polar (poly- $\varepsilon$ caprolactone, $\mathrm{PCL}$ ) matrices by electrospinning (ES). Electrospunable formulations were prepared with CS:NaCas (9:1 w/w ratio), at 2, 4 and 6 wt. \% in water, or PCL at 5, 10 and 15 wt.\% in glacial acetic acid using different $C A$ ratios $(0,5,10$ and 15 wt.\% with respect to the polymer). The liquid formulations were characterized for electrical conductivity, rheological behaviour and surface tension, and ES process conditions were established. The electrospun structures were analysed as to their nanostructure and CA retention. Geometry of the nanostructures obtained from the PCL systems was nanofibrillar with some beads, whereas it is particles that are mainly deposited for starch systems. PCL systems yielded better CA encapsulation efficiency (EE) than the polar ones, where greater variability was observed. The best EE (around $80 \%$ ) was obtained for $15 \%$ PCL regardless of the CA ratio.
\end{abstract}

\section{KEYWORDS}

Electrospinning; nanostructure; active compound; encapsulation efficiency.

\section{CHEMICAL COMPOUNDS}

Corn starch (PubChem CID: 24836924); Sodium Caseinate (PubChem CID: 73995022); Poly- $\varepsilon$-caprolactone (PubChem CID: 10401); Carvacrol (PubChem CID: 10364); Glacial acetic acid (PubChem CID: 73995022); Absolute ethanol (PubChem CID: 702).

\section{Introduction}

Microbial contamination and loss of nutrients due to oxidation are two of the major concerns of the food industry. An average per capita food losses of 280-300 kg/year in Europe and North-America was reported in a study carried out by The Swedish Institute for Food and Biotechnology (SIK) on behalf of the Food and Agriculture Organization of the United Nations (FAO, 2011). Significant percentage $(>50 \%)$ of these losses occurs early in the food supply chain, even before it reaches the final consumer. In an effort to reduce preconsumer food wastes, several alternatives are being under study. Among them, the use of active packaging material to enhance food preservation represents a promising technology. According to the Regulation (EC) No. 450/2009 (EU, 2009), active packaging materials are designed to purposely incorporate components that would interact with the packaged food or the environment surrounding it, extending its shelf life, while maintaining its quality. One possibility to incorporate these active agents into the packaging material is the use of multi-layered films, where one of these layers incorporates the active component. With a growing demand for a reduced use of synthetic antioxidants and preservatives coming in contact with the food, interest is focusing on natural based compounds, namely plant essential oils (EO) (Bakkali et al., 2008). Special attention is being paid to their active compounds (AC), terpenoid or phenolic in nature (Burt, 2004), which can provide

\footnotetext{
${ }^{1}$ Corresponding author. E-mail address: altam@upv.es (Alina Tampau).
} 
foodstuffs with antioxidant and antimicrobial protection (Rivera Calo et al., 2015; Ündeğer et al., 2009). Because of their volatility and degradability when exposed to light, oxygen and/or heat, these active compounds need to be encapsulated in matrices that retain them efficiently, protect them from degradation and allow their sustained release. Various methods of EO encapsulation have been investigated in the last few years, using different matrices and techniques. Some of the techniques that have been used consist of nanoprecipitation, coacervation, and encapsulation in liposomes, spray-drying and the rapid expansion of supercritical solutions (Asbahani et al., 2015).

Of the encapsulation methods, specific interest is currently being centred on electrospinning (ES) technology due to its ease of use, wide applicability (Bhardwaj and Kundu, 2010) and the possibility of obtaining structures that possess high surface-to-volume ratio (nanostructures) (Zhang et al., 2005). The versatility of this technology is proven by the growing number of applications and the variety of electrospunable materials (dissolutions or melts) being tested successfully (Bhardwaj and Kundu, 2010; Kim and Lee, 2000).

ES is a technique that uses electrostatic forces to create polymer fibres. The ES equipment consists of an electrically conductive needle tip or spinneret, a grounded collector and a power supply, responsible for generating the high voltage (around 5 to $50 \mathrm{kV}$ ). During the process, a polymer solution is loaded into the spinneret and held by its surface tension at the end of the capillary tip. As the intensity of the electric field increases, the hemispherical surface of the polymer solution at the tip of the capillary tube elongates to form a cone-shaped structure known as the Taylor cone. When the applied electric field reaches a critical value, the repulsive electrical forces exceed the surface tension forces, and the charged jet of the polymer solution is ejected from the tip of the Taylor cone, which becomes very long and thin. Meanwhile, the solvent evaporates leaving behind a charged polymer fibre which accelerates towards the collector of opposite polarity (Ghorani and Tucker, 2015).

Although initially the ES technique was employed to obtain fibres and filaments (Garg and Bowlin, 2011) and for medical purposes (drug delivery systems, tissue engineering (Hamori et al., 2014; Sill and von Recum, 2008; Wade and Burdick, 2014) and grafts (Ahn et al., 2015)), it is gaining ground in the field of food packaging, where the application of electrospun layers of different polymers on the film packaging surface, with or without active compounds, can provide the films with active or tailored functional properties (Fabra et al., 2016; Fabra et al., 2014; Wen et al., 2016). The absence of high temperatures during this process makes it very useful for encapsulating volatile or organic active agents that would otherwise lose their desirable properties (Ghorani and Tucker, 2015). The process allows for the creation of film-like structures (when fibres are electrospun) or the obtaining of a coating effect (electrospraying). Attempts to use natural, biodegradable polymers to obtain electrospun structures that can encapsulate active compounds (Bifidobacterium spp., cinnamaldehyde and cinnamon EO) have already been reported (López-Rubio et al., 2009; Rieger and Schiffman, 2014; Wen et al., 2016). Nevertheless, little information is available, and more research is needed in order to optimize the process for specific matrices and the AC they carry.

Of the natural antimicrobials, carvacrol (CA) is a monoterpenoid phenol found in the essential oil of oregano (Origanum vulgare), thyme (Thymus vulgaris L.), marjoram (Origanum majorana) and similar aromatic plants (De Vincenzi et al., 2004). Its antimicrobial effects have been proven with remarkable results on strains of bacteria, such as Escherichia coli, Staphylococcus aureus, Bacillus subtilis, Pseudomonas fluorescens (Ben Arfa, et al., 2006), Baccillus cereus (Ultee et al., 1998) and moulds, such as Penicillium notatum (Tunc et al., 2007). Studies into the antioxidant properties of CA reported that this compound is highly effective at protecting the cells, especially their DNA, from the damaging action of free radicals (Horvathova et al., 2014).

The incorporation of active compounds from EOs to hydrophilic biopolymer films requires the use of emulsifying techniques to obtain the film forming aqueous dispersions due to the hydrophobic nature of active compounds and their lack of water solubility. Afterwards, films are obtained by casting and subsequent drying under controlled conditions. During the drying step, a part of the water-immiscible active compounds 
evaporates by steam drag effect, depending on the system viscosity, lipid droplet size and emulsion stability (Perdones et al., 2016). The EO incorporation in biopolymer films during thermoplastic processing (melt blending, extrusion, etc.) also presents problems due to the high volatility and temperature sensitivity of these compounds (Chew and Nyam, 2016). Likewise, the fast release of active compounds embedded in polar biopolymers, in contact with aqueous systems as is the case in most of the foods, also represents a problem for the control of their sustained action (antimicrobial or antioxidant) and their sensory impact, associated with their usually strong flavour. In this sense, encapsulation of these kinds of compounds by ES and their application as an active layer in packaging films could represent a good alternative to control both the fast release and the sensory impact, since the delivered dose could be better optimized over time. Likewise, the functional properties of the films could be modulated, by combining hydrophobic (with high water barrier capacity) and hydrophilic (with high gas barrier capacity) materials in multilayer films (Fabra et al., 2016).

In this study, the capacity of polar and less polar polymers to encapsulate CA by ES has been analysed in order to use these kinds of electrospun layers as active coatings for packaging films. Of the available biopolymers, starch has the advantage of being widely available, low-cost and highly compatible in food applications, as well as being water soluble, with the subsequent advantages of using water as solvent. Nevertheless, its aqueous solutions exhibit high surface tension, which can negatively affect their electrospinning behaviour (Bhardwaj and Kundu, 2010). In this sense, blends of starch and proteins, such as sodium caseinate (NaCas), could offer more appropriate properties. On the other hand, the more hydrophobic poly- $\varepsilon$-caprolactone (PCL) exhibits very good electrospinning behaviour in glacial acetic acid (GAA) (Ferreira et al., 2014; Gholipour-Kanani and Bahrami, 2011) and could be highly effective as an encapsulating agent by using electrospinning (MartínezAbad et al., 2013).

The aim of this work is to analyse the CA encapsulation efficiency in two different polymer systems: polar (starch-sodium caseinate blends) and non-polar (PCL) dissolved in water and glacial acetic acid, respectively, as a function of the polymer concentration and the CA:polymer ratio. In this sense, the physical properties of the initial solutions/dispersions of components (polymer and active compound) relevant to the ES process were determined. Likewise, the microstructure of the electrospun material and the encapsulating efficacy of CA was analysed in each case and modelled as a function of the compositional variables of the initial dispersions or solutions.

\section{Materials and methods}

\subsection{Raw materials and reagents}

Corn starch (CS) (with 21\% amylose content) was purchased from Roquette (Roquette Laisa España, Benifaió (Valencia), Spain). NaCas, PCL and CA were supplied by Sigma (Sigma-Aldrich Chemie, Steinheim, Germany). Glacial acetic acid (GAA) and UV-grade absolute ethanol were obtained from Panreac (Panreac Química S.L.U., Castellar del Vallès (Barcelona), Spain). Purified water (with a resistivity of $18.2 \mathrm{M} \Omega \mathrm{cm}$ ) was obtained with a MilliQ Advantage A10 equipment from Millipore S.A.S., Molsheim, France.

\subsection{Preparation of formulations}

\section{Polar systems}

Starch dispersions $(2,4$ and $6 \% \mathrm{w} / \mathrm{w})$ were prepared by mixing 2,4 and $6 \mathrm{~g}$ respectively of CS with milli-Q water up to $100 \mathrm{~g}$ total weight. The dispersions were kept at $95^{\circ} \mathrm{C}$ for 30 minutes, with stirring, to allow the gelatinization of the polysaccharide. $\operatorname{NaCas}(2,4$ and $6 \%, w / w)$ was dissolved in milli-Q water using a magnetic stirrer (Model RCT Basic, IKA, Germany). Emulsions were then prepared by blending the respective starch and NaCas solution of the same concentration (in a ratio of 9:1) with CA, using different ratios of this compound: 0 , 
5, 10 and $15 \% \mathrm{w} / \mathrm{w}$ with respect to the total polymer content. Mixtures were thoroughly emulsified for 4 minutes using an Ultra Turrax rotor-stator homogenizer (Model T25D, IKA Germany) at 12,000 rpm. Thus, 12 different aqueous formulations were obtained.

\section{Non-polar systems}

PCL pellets were dissolved, under constant stirring for 24 hours, in GAA at 5, 10 and 15\% w/w and CA was added at $0,5,10$ and $15 \% \mathrm{w} / \mathrm{w}$ with respect to the polymer, thus obtaining 12 different non-polar formulations.

All formulations were prepared immediately prior to their analysis. Samples were coded as $\mathbf{P}_{\mathbf{i}} \mathbf{C}_{\mathrm{j}}$ or $\mathbf{N}_{\mathbf{i}} \mathbf{C}_{\mathrm{j}}$, where: $\mathbf{P}$ and $\mathbf{N}$ indicate a polar or non-polar system (polymer-solvent mixture), subscript $\mathbf{i}$ reflects the $\%$ of polymer in the solvent $(2,4$ or 6 for CS-NaCas blend and 5,10 or 15 for PCL) and subscript $\mathbf{j}$ stands for the $\%$ of CA with respect to the polymer content $(0,5,10$ or 15$)$. The concentration range of each polymer was established taking into account its solubility in the respective solvent and the limiting viscosity for the liquid flow in the equipment.

\subsection{Characterization of the initial solution/dispersion properties.}

Rheological behaviour was analyzed in duplicate at $25^{\circ} \mathrm{C}$, using a rotational rheometer (HAAKE Rheostress 1, Thermo Electric Corporation, Karlsruhe, Germany) with a sensor system of coaxial cylinders, type Z34DIN Ti. Measurements were taken between 0-200 s-1. The obtained data was fitted to the Ostwald de Waale power law model (eq. 1) in order to determine the consistency (K) and the flow behaviour indices (n).

$$
\sigma=K \cdot\left(\frac{\partial u}{\partial y}\right)^{n}(\text { eq.1) }
$$

where $\boldsymbol{\sigma}$ is the shear stress $(\mathrm{Pa}), \mathbf{K}$ is the flow consistency index $\left(\mathrm{Pa} \cdot \mathrm{s}^{\mathrm{n}}\right), \frac{\partial \boldsymbol{u}}{\partial \boldsymbol{y}}$ represents the shear rate $\left(\mathrm{s}^{-1}\right), \mathbf{n}$ is the flow behaviour index (dimensionless) ( $n=1$ Newtonian fluid, $n<1$ shear-thinning fluid, $n>1$ shear thickening fluid).

Particle size distribution of the starch based emulsions was carried out in triplicate using a laser diffractometer (MasterSizer, 2000; Malvern Instruments, Worcestershire, UK). The emulsions were dispersed in distilled water, at 2,000 rpm until an obscuration rate was obtained in the range 5-8\%. The volume-length mean diameter $\left(\mathrm{d}_{4,3}\right)$ was determined. $\zeta$-potential was also measured for the CA-water emulsions in triplicate using ZetaSizer nano series equipment (Malvern Instruments, Worcestershire, UK) with a DTS1070 cuvette. The Smoluchowski model (eq. 2) was selected to analyse the recorded data.

$$
v_{E}=4 \cdot \pi \cdot \varepsilon_{0} \cdot \varepsilon_{r} \cdot \frac{\zeta}{6 \cdot \pi \cdot \mu}(1+\kappa \cdot r)(\text { eq.2) }
$$

where $\varepsilon_{0}$ is the relative dielectric constant of a vacuum, $\varepsilon_{\mathrm{r}}$ is the electrical permittivity of a vacuum, $\zeta$ is the $\zeta$ potential, $\boldsymbol{\mu}$ is the solution viscosity, $\boldsymbol{r}$ represents the particle radius and $\boldsymbol{\kappa}$ is the Debye-Hückel parameter calculated as $\kappa=\sqrt{\frac{2 \cdot n_{0} \cdot z^{2} \cdot e^{2}}{\varepsilon_{r} \cdot \varepsilon_{0} \cdot k_{B} \cdot T}}$ (in which $\mathrm{n}_{0}$-the bulk ionic concentration, $\mathrm{z}$-the valence of the ion, e-the charge of an electron, $k_{\mathrm{B}}$-the Boltzmann constant and T-the absolute temperature)(Sze et al., 2003).

Electrical conductivity was measured for aqueous and GAA systems using a Mettler Toledo device, model SevenEasy Conductivity (Mettler Toledo, Schwerzenbach, Switzerland). Surface tension of liquid systems was 
analysed by means of the pendant drop method, using the OCA 20 instrument (Dataphysics, Germany), with SCA 20 Software package. Ten measurements were taken per formula.

\subsection{Electrospinning process}

The electrospinning of the liquid systems was carried out under ambient conditions $\left(25^{\circ} \mathrm{C}\right.$ and $\left.45 \% \mathrm{RH}\right)$ by using a Fluidnatek apparatus, acquired from Biolnicia S.L. (Valencia, Spain). The equipment presents a simple setup (Figure 1) that consists of a sample feeder (a $5 \mathrm{~mL}$ plastic Luer Lok syringe by BD Plastik), connected through a PTFE tube to a stainless-steel spinneret needle with an internal diameter of $0.6 \mathrm{~mm}$, a stainless-steel collector and a high voltage power supply $(0-30 \mathrm{KV})$. The flow rate of the liquid through the needle and the applied voltage were empirically fitted for each liquid to obtain a stable Taylor cone, on the basis of previously reported data (Gholipour-Kanani and Bahrami, 2011; Kong and Ziegler, 2012). Thus, the digitally controlled syringe fed the emulsions at a steady flow-rate that varied from 0.15 to $0,2 \mathrm{~mL} / \mathrm{h}$ for polar systems and from 0.4 to 1.2 for non-polar, while the needle was positioned horizontally $15 \mathrm{~cm}$ away from the collector. A voltage value between 12 and $22 \mathrm{kV}$ was applied for polar systems, whereas it ranged between 9.5 and 14.5 in non-polar systems.

\subsection{Characterization of electrospun products}

\section{Nanostructure of electrospun material}

Micrographs of the electrospun samples were obtained by means of Field Emission Scanning Electron Microscopy (FESEM Ultra 55, Zeiss, Oxford Instruments, UK). In order to microscopically analyse the obtained electrospun structures, the product was deposited over a support surface and stored in desiccators with phosphorus pentoxide $\left(\mathrm{P}_{2} \mathrm{O}_{5}\right)$ at $25^{\circ} \mathrm{C}$ prior to observation. Samples were mounted on support stubs and, after platinum coating, were observed using an accelerating voltage of $2 \mathrm{kV}$. Image analysis, by using the Image J software (National Institutes of Health, USA), was carried out to measure the size of particles and fibres in the obtained electrospun structures.

\section{Encapsulating efficiency of CA}

Degreased aluminium foils were used as support of the electrospun material from each formulation. Each foil was weighed before and after electrospinning the material for a determined time. Then, the coated foils were introduced into amber vials containing $15 \mathrm{~mL}$ of absolute ethanol, hermetically sealed and submitted to magnetic stirring for $24 \mathrm{~h}$ at room temperature to promote CA extraction. The extract was analyzed as to its CA content by using a UV/Vis spectrophotometer (Evolution 201 UV-Vis, Thermo Fisher Scientific Inc.) at 275 $\mathrm{nm}$. As blank, an extract of the respective polymer matrix without the $C A$ (samples $\mathrm{P}_{\mathrm{i}} \mathrm{C}_{0}$ and $\mathrm{N}_{\mathrm{l}} \mathrm{C}_{0}$, respectively) was used in each case. The results were expressed in $\mu \mathrm{g}$ carvacrol $/ \mathrm{mL}$ using the corresponding calibration curve for CA concentrations between $5-80 \mu \mathrm{g} / \mathrm{mL}$ (concentration= $x x x$ Absorbance, $r^{2}=0.999$ ). The encapsulating efficiency (in percentage) was determined through the quotient between the total extracted CA in the electrospun material and the theoretical CA content of the electrospun mass of each solution/dispersion liquid.

\subsection{Statistical analysis}

Statgraphics centurion XVI.I (StatPoint Technologies Inc., Warrenton, VA, USA) was used for data statistical analysis of variance (ANOVA) and the stepwise regression analysis for the EE and process variables.

\section{Results and discussion}

Properties of the carvacrol liquid formulations 
The physical properties of the liquid systems provide useful information for the purposes of understanding their electrospinning behavior. The morphology of the electrospun material is greatly affected by the viscosity of the solution (related to the concentration and the molecular weight of the polymer), surface tension, electrical conductivity and surface charge density of the solution, as well as by the processing parameters, such as voltage, flow rate and collectors ( $\mathrm{Li}$ and Wang, 2013). A suitable viscosity is required for electrospinning and it can be tuned by adjusting the polymer concentration of the solution. Both the polymer concentration and the subsequent viscosity of the liquid influence the stability of the Taylor cone and an optimal value of these parameters allows for the greater stability of the cone and jet during the process (Shastri et al., 2009). For solutions of low viscosity, the surface tension is the controlling factor which determines whether beads or beaded fibres are formed. By reducing the surface tension, for a determined concentration of the solution, beaded fibres can be converted into smooth fibres. Likewise, an increase in the solution conductivity favors the formation of thinner fibres. However, for natural polymers, which are generally polyelectrolytes, the ions increase the charge carrying ability of the polymer jet under the electric field, leading to poor fibre formation. Good ES results can be obtained when the liquid phase has low surface tension, which permits the use of a low voltage, thus obtaining thinner fibres (Garg and Bowlin, 2011) and increasing the surface-to-volume ratio of the formed structures.

The physical properties of the studied systems used to encapsulate CA by ES are very different, as shown in Tables 1, 2 and 3. Aqueous systems are CA emulsions, whereas non-polar blends are true dissolutions of PCL and CA in GAA. This aspect confers important differences in terms of their ability for electrospinning behavior.

For CA aqueous emulsions, the droplet size distributions are plotted in Figure 2 for the different formulations and their volume-length mean diameters $d_{4,3}$ are shown in Table 2. All of the emulsions presented a quasimonomodal particle distribution, showing small shoulders in some cases. In the case of samples without CA, it is remarkable that particles were also detected in the same size range $(20-50 \mu \mathrm{m})$ as that of CA emulsions and only small changes occurred when CA was incorporated at the different ratios. This indicates that starch and NaCas were not isolated, unfolded chains in water, but formed clusters measurable in size, while CA droplets seem to exhibit sizes in the same range. Samples with 2 and $6 \%$ polymer without CA exhibit a small fraction of bigger particles (aggregates) that disappeared when CA was incorporated, which implied a reduction in the mean diameter value $\left(d_{4,3}\right)$, regardless of the CA content. However, this effect was not observed for $4 \%$ polymer where the size distribution curves were broader but slightly shifted to smaller sizes. All aqueous systems contained negatively charged particles, as revealed by the $\zeta$-potential values. This is attributable to the surface action of negatively charged caseinate at the $\mathrm{pH}$ of the systems (average value 6.96), above its isoelectric point (ranging between 4.1 and 5.8, (Sigma Aldrich CAS 9005-46-3 information sheet)). The $\zeta$ potential values tend to increase when the CA ratio rises, which suggests that CA droplets competitively adsorb protein, reaching a greater surface charge, which will help to stabilize the emulsions through the promotion of the electrostatic repulsion and the steric effect. Such behaviour could be relevant to an enhancement of the encapsulating efficiency during electrospinning, since emulsion destabilization in the ESformed jet could lead to CA evaporation by means of the steam drag effect.

CA emulsions were also stabilized by the viscous effect, as revealed by the rheological parameters (Table 1). All of the polar formulations exhibited shear thinning $(n<1)$ behaviour, while all of the samples containing $6 \%$ polymer, or $4 \%$ polymer and 5 or $10 \% \mathrm{CA}$, exhibited time-dependent shear thinning (hysteresis loop within the up and down curves). This indicates that weak gel structures are formed when the polymer reaches $6 \%$, or total CA content exceeds $0.30 \%$ in the emulsion. This weak gel breaks down through the disaggregation of chains and droplets occurring under shear rate conditions. This flocculation could negatively affect the behaviour of the ES, since the capacity of macromolecules to unfold during the jet formation, favouring adequate solvent evaporation, would be limited. As expected, $K$ values increased when the polymer concentration rose, whereas the incorporation of CA has a different effect, depending on the polymer 
concentration. 5\% CA hardly affected the rheological behaviour of $2 \%$ polymer dispersions, whereas it promoted consistency when the polymer was at 4 or $6 \%$. Nevertheless, in general, the addition of CA enhanced the shear thinning behaviour and consistency index of the liquid systems in line with its ratio increase, this being especially remarkable for emulsions with $4 \%$ polymer. This suggests that CA-Polymer interactions were promoted to a different extent, depending on the total content of both components in the blend.

For the non-polar systems, polymer-CA solutions exhibited Newtonian behaviour in every case and the obtained viscosity values are shown in Table 1 . The viscosity of these solutions was basically determined by the $\mathrm{PCL}$ concentration and no relevant changes were induced by adding CA in the studied concentration range. These viscosity values ranged between 0.39-1.49 Pa.s. Taking into account the very low shear rate acting in the needle (range: 0.6-1.8 $\mathrm{s}^{-1}$ ), estimated through the flow rates and the needle internal diameter, the apparent viscosity at $1 \mathrm{~s}^{-1}$ (equal to the $\mathrm{K}$ value) could be used to compare the flow resistance of both kinds of fluids. These values ranged between 0.006 and 3.35 , which cover a wider range of consistency than that obtained in non-polar systems. The consistency index of polar dispersions with $6 \%$ polymer and CA exceeded the upper viscosity limit of the non-polar solutions.

Every polar formulation showed surface tension values (Table 3) which were significantly lower than those of the solvent $(72 \mathrm{mN} / \mathrm{m})$. Likewise, an increase in polymer concentration provoked a decrease in the surface tension in line with the surfactant effect of protein at the interface. The incorporation of the smallest amount of CA led to a significant surfactant effect, which could be explained by its interaction with protein, affecting its surface adsorption capacity; however, the increase in the CA content did not produce any additional effects, except for the higher protein content where a greater reduction in surface tension was observed when the CA ratio rose. Thus, this parameter ranged from 54 to $30 \mathrm{~m} \mathrm{~N} \mathrm{~m}^{-1}$ in the different polar systems. On the contrary, the surface tension values were very homogenous $(25-27 \mathrm{mN} / \mathrm{m})$ in the non-polar systems, these being in the range of the values of pure GAA $\left(27.10 \mathrm{mN} / \mathrm{m}\right.$ at $25^{\circ} \mathrm{C}$, Haynes, 2013-2014). So, no relevant surfactant action of PCL or CA can be deduced from the obtained surface tension values, according to their good solubility in the GGA.

The conductivity values of the different systems are shown in Table 3 where, as expected, the much higher values of the aqueous systems can be observed. In polar dispersions, the conductivity values increased when the polymer content rose which must be attributable to the greater ionic strength associated with the caseinate content; at the highest concentration, however, a reduction was observed associated with the fact that ion mobility was more limited as a consequence of the effects of aggregation and the higher viscosity. The addition of CA implied a slight decrease in the conductivity values for a determined polymer concentration, which could be attributed to different effects, such as a viscosity increase, changes in the mobility of the charged species or the attenuation of the electric field in the presence of a greater fraction of non-polar dispersed phase. Most of the lipid components are not conductive and interfere with the salts, thereby reducing their conducting power (Mucchetti et al., 1994). The conductivity values of non-polar solutions were affected by the polymer concentration and, to a much lesser extent, by the CA content. The conductivity increased (twice) when PCL reached $10 \%$ in GAA, but decreased at $15 \%$, nearly to the value obtained for $5 \%$, probably due to the viscous effects. The addition of $C A$ enhanced solution conductivity for the smallest ratio $(5 \%)$, but reduced it for the highest. All of the values were about ten times higher than that of pure GAA $\left(0.0112 \mu \mathrm{S} / \mathrm{cm}\right.$ at $25^{\circ} \mathrm{C}$ ) (Dean and Lange, 1999). Trace amounts of water from the polymer could be responsible for these differences, since small amounts of water greatly modify the electrical conductivity of GAA (Analytical, 2010).

\subsection{Characterization of the electrospun product}


The morphology of the material electrospun from polar and non-polar systems is shown in Figures 3 and 4, respectively. Great microstructural differences can be observed for starch and PCL based matrices. PCL matrices showed a bead-and-tail morphology, depending on the polymer concentration, whereas a more undefined bead structure was obtained for a large proportion of the starch formulations, as previously reported by Li et al., (2016) for electrospun native starch material. Excepting the dispersions with $4 \%$ polymer and 10 or $15 \% \mathrm{CA}$, quite unstructured material was obtained for the rest of the aqueous systems, exhibiting the typical appearance of a wet deposition due to the non-efficient water evaporation in the jet formed. These products adhered weakly to the collector and detached from its surface as a non-sticky powder. The poor electrospinning behaviour of emulsions with 2 or $6 \%$ polymer might mainly be due to the very low viscosity of the first and to the flocculation that occurs to a great extent in the second. This implied the formation of an unstable Taylor cone and a non-homogeneous jet. An intermediate concentration of polymer (4\%) better fits the viscosity requirements for electrospinning and also exhibits higher conductivity values. The greatest ratios of CA (10 and $15 \%$ ) also promote flow viscosity and seem to favour the beaded fibre formation. With the increase in polymer content, more fibrous structures were expected. However, for the series with $6 \%$ polymer, the rheological behaviour indicated weak gel formation, which makes jet stabilization and stretching difficult, leading to the formation of irregular round-shaped particles on the collector. Likewise, even in samples with good electrospinning behaviour and $4 \%$ polymer, the macromolecules did not wrap and form fibres but beads. Kong and Ziegler (2014) attributed the appearance of discrete structures in electrospun starch to the inability of the amylose helices to unfold fully during the process. Only when a complete helix-to-coil transition occurs, do the required entanglements occur and the polymer can be electrospun into continuous fibres. On the other hand, the branched amylopectin does not exhibit properties suitable for unfolding and entangling, as reported by the same authors for amylopectin-rich native starches. Blends with NaCas and CA did not notably improve the electrospinning behaviour of starch in the conditions that could be applied. The flow rate was between 0.1 and $0.2 \mathrm{~mL} / \mathrm{h}$ and the voltage ranged from 12 to $22 \mathrm{kV}$, depending on the polymer and CA concentrations. The highest flow rate was required to process dispersions with $4 \%$ polymer, whereas the greatest voltage was applied for those containing $2 \%$ polymer. In contrast, a higher flow rate could be applied in non-polar systems (0.4 to $1.2 \mathrm{~mL} / \mathrm{h}$ ) with a lower voltage (9.5 to $14.5 \mathrm{kV}$ ); the higher the PCL and CA concentrations, the greater the flow rate and the lower the voltage.

No evidence of CA droplets was observed in starch-based electrospun material, which indicates that the compound was intimately absorbed in the polymer structure. Carvacrol could be entrapped in the central cavity of the single-helical V-amylose molecules, similarly to the structure formed by cyclodextrins when used to encapsulate lipophilic substances (Itthisoponkul et al., 2007).

Figure 4 shows the morphology of the material electrospun from the GAA-PCL systems, when a much more defined microstructure could be observed. In general, microstructure shows a mesh of fibres with entrapped bead formations, although fewer fibres were obtained at the lowest PCL concentration, in line with the lowest viscosity. The increase in the CA ratio for a determined polymer concentration also reduced the fibre formation, promoting the beads, which could be related with the interactions of CA with the polymer chains that make the chain unfolding more difficult. At very high magnification, it was noted that the beads are an entanglement of nanofibres. With the increase in polymer content, the beads exhibited more elongated shapes, probably due to the stretching of the more viscous jet by the electric forces, and more fibres were formed. A higher polymer concentration also gave rise to thicker fibres, as reported by Kanani and Bahrami (2011) for PCL dissolved in GAA at similar concentration levels, which was attributed to the promotion of the polymer chain entanglements when the concentration rose in the solution. On the basis of the obtained microstructure, the ability of PCL solutions with CA to be electrospun was much better than that of starchbased aqueous systems, despite the low electrical conductivity values. Nevertheless, the viscosity and surface tension values were adequate for this purpose and the linearity of the chain greatly favours the development of electrospinning. In fact, the element size analysis of the electrospun material revealed a more 
nanostructured arrangement for PCL samples. In the polar systems, for cases with fibre formation, diameters of the obtained structures ranged between $40 \mathrm{~nm}$ (for the fibres) and $3.4 \mu \mathrm{m}$ (for spherical morphologies), while in the non-polar systems, fibres exhibited diameters ranging between $15.0 \mathrm{~nm}$ and $1.4 \mu \mathrm{m}$ and beads with diameters spanning from $0.25 \mu \mathrm{m}$ up to $25 \mu \mathrm{m}$ (maximum diameter in the case of the elongated structures).

\subsubsection{CA encapsulation efficiency}

The potential of both polar and non-polar polymer matrices to encapsulate CA when electrospun is shown in Figure 5. The percentage of CA retained in the matrix, in relation to that originally present in the electrospun dispersion, was plotted as a function of the polymer concentration in the dispersion/solution for the different ratios of CA. It was noted that for the starch-based system, the percentage of retention is relatively low and is heavily dependent on the polymer concentration, while exhibiting a high degree of variation, as compared to the values in the PCL-GAA system, where higher polymer concentrations could be used on the basis of the greater PCL solubility in GAA. The variation in the values could be explained by the steam drag effect of $C A$ with water evaporation due to the immiscibility of CA in water, which provokes the evaporation of CA-water mixtures at a temperature lower than that of pure water (steam distillation). Polymer adsorption on the surface of CA droplets could limit this effect during the jet stretching, but destabilization phenomena of the emulsion during the process will enhance the CA steam drag. Likewise, the limited compatibility of CA with the more polar matrix (starch-NaCas) could contribute to the less effective CA retention. Using this aqueous system, the retention capacity varied from $15-75 \%$, depending on the polymer content and CA ratio. The increase in the polymer concentration improved the encapsulation capacity of the matrix, which could be explained by the promotion of viscosity, which enhances the viscous stabilization of the emulsified CA, thus limiting the steam drag effect. The greatest $C A$ retention occurred with the highest polymer concentration and CA ratio. It should be mentioned that the CA retained in the matrix could be both included inside the electrospun droplets and fibres and on the surface of these structures. Nevertheless, it was assumed that the carvacrol extracted from the fibres was effectively encapsulated since, given the volatile nature of the compound, the amount retained at surface level would evaporate quickly and it would be not present when the methanol extraction was carried out to quantify the encapsulated ratio in the fibres.

A stepwise regression analyses was carried out in order to evaluate the influence of independent variables, both physical properties and compositional variables (polymer concentration and carvacrol polymer ratio in the initial solution) on the encapsulation efficiency of carvacrol (dependent variable). Given the different range of the independent variables for polar and non-polar systems, the analyses were carried separately for each kind of system. A second grade polynomial model was considered in each case, thus taking lineal and square terms, to identity potential interactions between independent variables. The stepwise regression procedure allows for eliminating the polynomial terms without statistical significance in the model, thus giving a more simple equation with the minimum prediction error, where only variables with statistical significance appeared in the equation.

For polar system, eq. 3 was obtained for the EE as a function of the physical properties of liquid dispersions (surface tension, consistency index and conductivity). This regression revealed that the three considered properties affected the EE, but the properties that had the greatest statistical significance ( $p$ value) in the model were consistency index and conductivity.

$$
\% \mathrm{EE}=-1.7 K \gamma+0.5 K \kappa+1.5 \kappa-9 \gamma-14 K^{2}-0.004 \kappa^{2}+0.16 \gamma^{2}\left(R^{2}=98.31\right) \text { (eq.3) }
$$

When using the non-polar system, a greater EE was obtained, up to $50-86 \%$, which increased when the polymer concentration rose, as observed in the case of the polar systems. The best CA retention (>80\%) was reached when $15 \% \mathrm{PCL}$ and $15 \% \mathrm{CA}$ were used, with very small differences when the other CA ratio was employed. When non-polar systems contained 5 and $10 \%$ CA with respect to the polymer, no differences in 
the $\mathrm{CA}$ retention behaviour were observed, showing a limited effect of the polymer concentration on the EE. However, with $15 \% \mathrm{CA}$, the percentage of retention was more sensitive to the polymer concentration, probably due to the fact that the capacity of the polymer matrix to entrap the greatest amount of the compound was limited.

In contrast to the polar system, the stepwise regression analysis revealed that the surface tension $(\gamma)$ and the products of viscosity $(\boldsymbol{\mu})$ and conductivity $(\boldsymbol{\kappa})$ or surface tension are the properties with the greatest statistical significance in the obtained model for the non-polar systems (eq. 4).

$$
\% \mathrm{EE}=565 \mu \kappa-2.5 \mu \gamma-44 \kappa \gamma+885 \kappa+0.161 \gamma^{2}\left(R^{2}=99.86\right)(\text { eq.4) }
$$

Predictive equations of $\mathrm{EE}$ as a function of the polymer concentration and $\mathrm{CA}$ ratio in the liquid system for polar and non-polar systems were also obtained (eqs. 5 and 6, respectively). These equations fit the experimental points shown in Figure 5 for polar and non-polar systems, with a standard error of the estimate of 7 and $5 \%$, respectively, allowing for obtaining good predicted values of the EE. From the predicted EE value, the load of CA in the electrospun polymer ( $\mathrm{g} \mathrm{CA} / \mathrm{g}$ polymer) can be estimated by multiplying it by the nominal ratio in the initial solution.

$$
\begin{aligned}
& \% \mathrm{EE}=3(\% \text { polymer })^{2}-0.4(\% C A)^{2}-15(\% \text { polymer })+10(\% C A)\left(R^{2}=98.07\right) \text { (eq. 5) } \\
& \% \mathrm{EE}=11(\% \text { polymer })+4(\% \mathrm{CA})-0.47(\% \text { polymer })^{2}-0.24(\% C A)^{2}\left(R^{2}=99.65\right) \text { (eq. 6) }
\end{aligned}
$$

The capacity of the polymer matrix to entrap CA could be better observed in Figure 6, where the amount of CA retained per mass unit of polymer can be observed for the different conditions tested. An upward trend in the CA load in the polymer when the polymer concentration rose in the liquid system can be observed for all CA: polymer ratios. Nevertheless, this was more marked when the CA ratio increased in the liquid system with respect to the polymer. This points to both the greater viscosity requirements for CA encapsulation when its ratio rises with respect to the polymer and to the key role that viscosity plays in the outcome of the electrospinning process when employed to encapsulate these kinds of compounds.

The obtained results allow for selecting the adequate concentrations and ratios of polymer and active to reach the maximum EE. In this sense, using non-polar system, it is recommended that the highest concentrations of PCL and CA be used in the liquid system in order to obtain a good CA load in the matrix, while the process time needed to obtain a determined amount of coating material is shorter, since the process yield increases when a lower amount of solvent is evaporated. Likewise, for a given flow rate and electrospinning time of the optimum solution/dispersion on a defined surface, it is possible to determine the surface density $\left(\mathrm{g} / \mathrm{cm}^{2}\right)$ of the electrospun material and the surface density of active compound $\left(\mathrm{g} / \mathrm{cm}^{2}\right)$ by applying the obtained equations for EE. In this way, the available active compound per surface unit of a electrospun film can be predicted in order to evaluate if it exceeds or not the necessary concentration for inhibiting microbial growth. However, other factors must be taken into account. Namely, the required dose of the active compound applied to a determined food system from an electrospun active packaging film will depend on several factors: 1) the amount of carvacrol per mass unit of electrospun fibre, which in turn, is affected by the encapsulation efficiency of the polymer; 2 ) the flow rate and time of electrospinning process which determine the thickness of the electrospun layer and the mass of fibre per surface unit in the film, 3) the minimally inhibitory concentration (MIC) of the active for a target microorganism, 4) the active release capacity from the fibre into a determined food system, according to the respective affinity or partition coefficient and 5) the interactions of the active within the food matrix which can affect its antimicrobial activity. The obtained results are relevant to predict the active concentration per surface unit of active film for a determined flow rate and time of the electrospinning process. Nevertheless, release studies and in vitro and in vivo antimicrobial tests are required for a complete assessment of the active film development. Likewise, sensory evaluation of the 
potential impact of the active on the food system organoleptic properties is required to guarantee food quality.

\section{Conclusions}

Greater CA encapsulating efficiency (>80\%), with lower variability, was obtained for the PCL-based systems than for the starch-based ones. This may be explained by different factors: the greater solubility of PCL in GAA, allowing for the use of higher polymer concentrations with adequate viscosity, the greater compatibility of CA and PCL and the linearity of the polymer chain, which permits the chain to unfold in the electric field and its subsequent entanglement to form fibres. This nanostructure presented better cohesiveness and adhesiveness in the electrospun material, which also contribute to the coating performance. The lower variability in the CA retention, associated with the lack of water in the liquid systems, which helps to avoid steam drag effects, also represents an advantage with respect to the aqueous systems. Therefore, in order to obtain tightly adhered electrospun layers with the highest CA load in the matrix, it is recommended that the highest $\mathrm{PCL}$ concentration (15\%) and CA ratio (15\%) be used.

\section{Acknowledgments}

The authors would like to thank the Ministerio de Economia y Competitividad of Spain, for funding this study as part of projects AGL2013-42989-R and AGL2016-76699-R and predoctoral research grant \# BES-2014068100.

\section{Bibliography}

Ahn, H., Ju, Y. M., Takahashi, H., Williams, D. F., Yoo, J. J., Lee, S. J., Atala, A. (2015). Engineered small diameter vascular grafts by combining cell sheet engineering and electrospinning technology. Acta Biomaterialia, 16(1), 14-22. https://doi.org/10.1016/j.actbio.2015.01.030

Analytical, R. (2010). Conductance Data For Commonly Used Chemicals. Emerson Process Management, (December), 44-6039/rev. B, 6.

http://www.emerson.com/resource/blob/68896/20a2feae1092b9763fee29d39c49a5a7/manual-conductance-data-for-commonly-used-chemicals-data.pdf

Asbahani, A. El, Miladi, K., Badri, W., Sala, M., Addi, E. H. A., Casabianca, H., Elaissari, A. (2015). Essential oils: From extraction to encapsulation. International Journal of Pharmaceutics, 483(1-2), 220-243. https://doi.org/10.1016/j.ijpharm.2014.12.069

Bahrami, S. H., \& Gholipour Kanani, A. (2011). Effect of changing solvents on poly( $\varepsilon$-Caprolactone) nanofibrous webs morphology. Journal of Nanomaterials, 2011. https://doi.org/10.1155/2011/724153

Bakkali, F., Averbeck, S., Averbeck, D., \& Idaomar, M. (2008). Biological effects of essential oils- A review. Food and Chemical Toxocology. https://doi.org/10.1016/j.fct.2007.09.106

Ben Arfa, A., Combes, S., Preziosi-Belloy, L., Gontard, N., \& Chalier, P. (2006). Antimicrobial activity of carvacrol related to its chemical structure. Letters in Applied Microbiology, 43(2), 149-154. https://doi.org/10.1111/j.1472-765X.2006.01938.x

Bhardwaj, N., \& Kundu, S. C. (2010). Electrospinning: A fascinating fiber fabrication technique. Biotechnology Advances, 28(3), 325-347. https://doi.org/10.1016/j.biotechadv.2010.01.004 
Burt, S (2004). Essential oils: their antibacterial properties and potential applications in foods-a review. International Journal of Food Microbiology 94 (3) 223- 253

http://dx.doi.org/10.1016/j.ijfoodmicro.2004.03.022

Calo, J. R., Crandall, P. G., O’Bryan, C. A., \& Ricke, S. C. (2015). Essential oils as antimicrobials in food systems A review. Food Control, 54, 111-119. https://doi.org/10.1016/j.foodcont.2014.12.040

Chew, S. C., \& Nyam, K. L. (2016). Microencapsulation of kenaf seed oil by co-extrusion technology. Journal of Food Engineering, 175, 43-50. https://doi.org/10.1016/j.jfoodeng.2015.12.002

Dean, J. A., \& Lange, N. A. (1999). Lange's Handbook of Chemistry. McGraw-Hill. table 8.34, 8.161-8.162

De Vincenzi, M., Stammati, A., De Vincenzi, A., \& Silano, M. (2004). Constituents of aromatic plants: Carvacrol. Fitoterapia, 75(7-8), 801-804.

https://doi.org/10.1016/j.fitote.2004.05.002

EU, (2009). Guidance to the commission regulation (EC) No 450/2009 of 29 May 2009 on active and intelligent materials and articles intended to come into contact with food. Version 10. European Commission Health and Consumers Directorate-General Directorate E-Safety of the Food chain. E6 - Innovation and sustainability.

http://eur-lex.europa.eu/legal-content/EN/ALL/?uri=CELEX\%3A32009R0450

Fabra, M. J., López-Rubio, A., \& Lagaron, J. M. (2016). Use of the electrohydrodynamic process to develop active/bioactive bilayer films for food packaging applications. Food Hydrocolloids, 55, 11-18.

https://doi.org/10.1016/j.foodhyd.2015.10.026

Fabra, M. J., López-Rubio, A., \& Lagaron, J. M. (2014). On the use of different hydrocolloids as electrospun adhesive interlayers to enhance the barrier properties of polyhydroxyalkanoates of interest in fully renewable food packaging concepts. Food Hydrocolloids, 39, 77-84.

https://doi.org/10.1016/j.foodhyd.2013.12.023

FAO. (2011). Global food losses and food waste - Extent, causes and prevention. Rome

Ferreira, J. L., Gomes, S., Henriques, C., Borges, J. P., \& Silva, J. C. (2014). Electrospinning polycaprolactone dissolved in glacial acetic acid: Fiber production, nonwoven characterization, and In Vitro evaluation. Journal of Applied Polymer Science, (September 2016).

https://doi.org/10.1002/app.41068

Garg, K., \& Bowlin, G. L. (2011). Electrospinning jets and nanofibrous structures. Biomicrofluidics, 5(1), 1-19. https://doi.org/10.1063/1.3567097

Ghorani, B., \& Tucker, N. (2015). Fundamentals of electrospinning as a novel delivery vehicle for bioactive compounds in food nanotechnology. Food Hydrocolloids, 51, 227-240.

https://doi.org/10.1016/j.foodhyd.2015.05.024

Hamori, M., Yoshimatsu, S., Hukuchi, Y., Shimizu, Y., Fukushima, K., Sugioka, N., Shibata, N. (2014). Preparation and pharmaceutical evaluation of nano-fiber matrix supported drug delivery system using the solventbased electrospinning method. International Journal of Pharmaceutics, 464(1-2), 243-251. https://doi.org/10.1016/j.ijpharm.2013.12.036

Haynes, W.M. (ed.) (2013-2014). CRC Handbook of Chemistry and Physics. 94th Edition. CRC Press LLC, Boca Raton: FL, 6-182. https://toxnet.nlm.nih.gov/cgi-bin/sis/search2/r?dbs+hsdb:@term+@rn+@rel+64-19-7

Horvathova, E., Navarova, J., Galova, E., Sevcovicova, A., Chodakova, L., Snahnicanova, Z., ... Slamenova, D. (2014). Assessment of antioxidative, chelating, and DNA-Protective effects of selected essential oil 
components (Eugenol, Carvacrol, Thymol, Borneol, Eucalyptol) of plants and intact rosmarinus officinalis oil. Journal of Agricultural and Food Chemistry, 62(28), 6632-6639.

https://doi.org/10.1021/jf501006y

Itthisoponkul, T., Mitchell, J. R., Taylor, A. J., \& Farhat, I. A. (2007). Inclusion complexes of tapioca starch with flavour compounds. Carbohydrate Polymers, 69(1), 106-115.

https://doi.org/10.1016/j.carbpol.2006.09.012

Kim, J. S., \& Lee, D. (2000). Thermal properties of electrospun polyesters. Polymer Journal. https://doi.org/10.1295/polymj.32.616

Kong, L., \& Ziegler, G. R. (2014). Fabrication of pure starch fibers by electrospinning. Food Hydrocolloids, 36, 20-25. https://doi.org/10.1016/j.foodhyd.2013.08.021

Kong, L., \& Ziegler, G. R. (2012). Role of molecular entanglements in starch fiber formation by electrospinning. Biomacromolecules, 13(8), 2247-2253.

https://doi.org/10.1021/bm300396j

Li, X., Chen, H., \& Yang, B. (2016). Centrifugally spun starch-based fibers from amylopectin rich starches. Carbohydrate Polymers, 137, 459-465. https://doi.org/10.1016/j.carbpol.2015.10.079

Li, Z., \& Wang, C. (2013). One-Dimensional nanostructures, 15-29. https://doi.org/10.1007/978-3-642-36427-3

López-Rubio, A., Sanchez, E., Sanz, Y., \& Lagaron, J. M. (2009). Encapsulation of living bifidobacteria in ultrathin PVOH electrospun fibers. Biomacromolecules, 10(10), 2823-2829. https://doi.org/10.1021/bm900660b

Martínez-Abad, A., Sánchez, G., Fuster, V., Lagaron, J. M., \& Ocio, M. J. (2013). Antibacterial performance of solvent cast polycaprolactone (PCL) films containing essential oils. Food Control, 34(1), 214-220. https://doi.org/10.1016/j.foodcont.2013.04.025

Mucchetti, G., Gatti, M., \& Neviani, E. (1994). Electrical Conductivity Changes in Milk Caused by Acidification: Determining Factors. Journal of Dairy Science, 77(4), 940-944. https://doi.org/http://dx.doi.org/10.3168/jds.S0022-0302(94)77029-6

Perdones, Á., Chiralt, A., \& Vargas, M. (2016). Properties of film-forming dispersions and films based on chitosan containing basil or thyme essential oil. Food Hydrocolloids, 57, 271-279. https://doi.org/10.1016/j.foodhyd.2016.02.006

Rieger, K. A., \& Schiffman, J. D. (2014). Electrospinning an essential oil: Cinnamaldehyde enhances the antimicrobial efficacy of chitosan/poly (ethylene oxide) nanofibers. Carbohydrate Polymers, 113, 561568. https://doi.org/10.1016/j.carbpol.2014.06.075

Shastri, V. P., Sy, J. C., \& Klemm, A. S. (2009). Emulsion as a means of controlling electrospinning of polymers. Advanced Materials, 21(18), 1814-1819. https://doi.org/10.1002/adma.200701630

Sigma Aldrich CAS 9005-46-3 information sheet http://www.sigmaaldrich.com/content/dam/sigmaaldrich/docs/Sigma/Product_Information_Sheet/c8654pis.pdf

Sill, T. J., \& von Recum, H. A. (2008). Electrospinning: Applications in drug delivery and tissue engineering. Biomaterials, 29(13), 1989-2006.

https://doi.org/10.1016/j.biomaterials.2008.01.011 
Sze, A., Erickson, D., Ren, L., \& Li, D. (2003). Zeta-potential measurement using the Smoluchowski equation and the slope of the current - time relationship in electroosmotic flow. Journal of Colloid and Interface Science, 261, 402-410.

https://doi.org/10.1016/S0021-9797(03)00142-5

Tunc, S., Chollet, E., Chalier, P., Preziosi-Belloy, L., \& Gontard, N. (2007). Combined effect of volatile antimicrobial agents on the growth of Penicillium notatum. International Journal of Food Microbiology, 113(3), 263-270. https://doi.org/10.1016/j.ijfoodmicro.2006.07.004

Ultee, A., Gorris, L. G. M., \& Smid, E. J. (1998). Bactericidal activity of carvacrol towards the food-borne pathogen Bacillus cereus. Journal of Applied Microbiology, 85(2), 211-218. https://doi.org/10.1046/j.1365-2672.1998.00467.x

Ündeğer, Ü., Başaran, A., Degen, G. H., \& Başaran, N. (2009). Antioxidant activities of major thyme ingredients and lack of (oxidative) DNA damage in V79 Chinese hamster lung fibroblast cells at low levels of carvacrol and thymol. Food and Chemical Toxicology, 47(8), 2037-2043.

https://doi.org/10.1016/j.fct.2009.05.020

Wade, R. J., \& Burdick, J. a. (2014). Advances in nanofibrous scaffolds for biomedical applications: From electrospinning to self-assembly. Nano Today, 9(6), 722-742.

https://doi.org/10.1016/j.nantod.2014.10.002

Wen, P., Zhu, D.-H., Wu, H., Zong, M.-H., Jing, Y.-R., \& Han, S.-Y. (2016). Encapsulation of cinnamon essential oil in electrospun nanofibrous film for active food packaging. Food Control, 59, 366-376.

https://doi.org/10.1016/j.foodcont.2015.06.005

Zhang, Y., Chwee, T. L., Ramakrishna, S., \& Huang, Z. M. (2005). Recent development of polymer nanofibers for biomedical and biotechnological applications. Journal of Materials Science: Materials in Medicine, 16(10), 933-946. https://doi.org/10.1007/s10856-005-4428-x 
Table 1: Rheological parameters for both polar and non-polar series: flow behaviour index (n), consistency index $\left(\mathrm{K}\left[\mathrm{Pa} \cdot \mathrm{s}^{\mathrm{n}}\right]\right)$ and viscosity $(\mu[\mathrm{Pa} \cdot \mathrm{s}])$. Average values and standard deviations.

\begin{tabular}{|c|c|c|c|c|c|c|c|c|c|}
\hline & \multicolumn{8}{|c|}{ Polymer concentration (\%) } \\
\hline & & \multicolumn{4}{|c|}{ Polar system } & \multicolumn{4}{|c|}{ Non-polar system } \\
\hline & & & 2 & 4 & 6 & & 5 & 10 & 15 \\
\hline \multirow{4}{*}{ 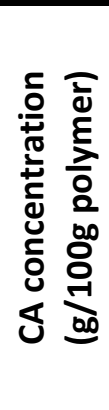 } & 0 & $\begin{array}{l}\mathrm{n} \\
\mathrm{K} \\
\end{array}$ & $\begin{array}{c}0.93 \pm 0.05^{\mathrm{e}} \\
0.0064 \pm 0.0009^{\mathrm{a}} \\
\end{array}$ & $\begin{array}{c}0.85 \pm 0.07^{\text {de }} \\
0.034 \pm 0.013^{\mathrm{a}}\end{array}$ & $\begin{array}{c}0.48 \pm 0.03^{b} \\
1.3 \pm 0.2^{b c}\end{array}$ & \multirow{4}{*}{$\begin{array}{l}\bar{y} \\
\dot{\delta} \\
\underline{0} \\
\underline{z}\end{array}$} & $0.0389 \pm 0.0007^{a}$ & $0.499 \pm 0.002^{c}$ & $1.464 \pm 0.002^{\mathrm{e}}$ \\
\hline & 5 & \begin{tabular}{|l|}
$\mathbf{n}$ \\
$\mathrm{K}$ \\
\end{tabular} & $\begin{array}{c}0.86 \pm 0.08^{\mathrm{de}} \\
0.008 \pm 0.003^{\mathrm{a}}\end{array}$ & $\begin{array}{l}0.65 \pm 0.02^{\mathrm{c}} \\
0.15 \pm 0.02^{\mathrm{a}}\end{array}$ & $\begin{array}{c}0.40 \pm 0.02^{\mathrm{ab}} \\
2.3 \pm 0.9^{\mathrm{d}}\end{array}$ & & $0.0393 \pm 0.0013^{a}$ & $0.480 \pm 0.014^{b}$ & $1.483 \pm 0.002^{f}$ \\
\hline & 10 & $\begin{array}{l}\mathbf{n} \\
\mathbf{k}\end{array}$ & $\begin{array}{c}0.85 \pm 0.04^{\text {de }} \\
0.008 \pm 0.002^{a}\end{array}$ & $\begin{array}{c}0.466 \pm 0.014^{\mathrm{b}} \\
0.58 \pm 0.14^{\mathrm{ab}}\end{array}$ & $\begin{array}{c}0.409 \pm 0.011^{\mathrm{ab}} \\
1.9 \pm 0.2^{\mathrm{cd}}\end{array}$ & & $0.0424 \pm 0.0006^{a}$ & $\begin{array}{c}0.5003 \pm 0.0008 \\
c\end{array}$ & $1.4983 \pm 0.0007^{\mathrm{g}}$ \\
\hline & 15 & $\begin{array}{l}\mathrm{n} \\
\mathrm{K}\end{array}$ & $\begin{array}{c}0.81 \pm 0.05^{d} \\
0.013 \pm 0.003^{a}\end{array}$ & $\begin{array}{c}0.429 \pm 0.003^{\mathrm{ab}} \\
0.72 \pm 0.04^{\mathrm{ab}}\end{array}$ & $\begin{array}{c}0.37 \pm 0.02^{\mathrm{a}} \\
3.4 \pm 0.8^{\mathrm{e}} \\
\end{array}$ & & $0.0398 \pm 0.0006^{a}$ & $0.499 \pm 0.003^{c}$ & $1.434 \pm 0.003^{d}$ \\
\hline
\end{tabular}

Different superscripts $(a, b, c .$.$) in each series indicate significant differences according to ANOVA test (p<0.05)$ for the respective parameter.

Table 2: Emulsion properties for polar series: particle volume-length mean diameter $\left(\boldsymbol{d}_{4,3}\right), \boldsymbol{d}_{4,3}-\boldsymbol{d}_{3,2}$ difference and $\zeta$-potential of the particles. Average values and standard deviations.

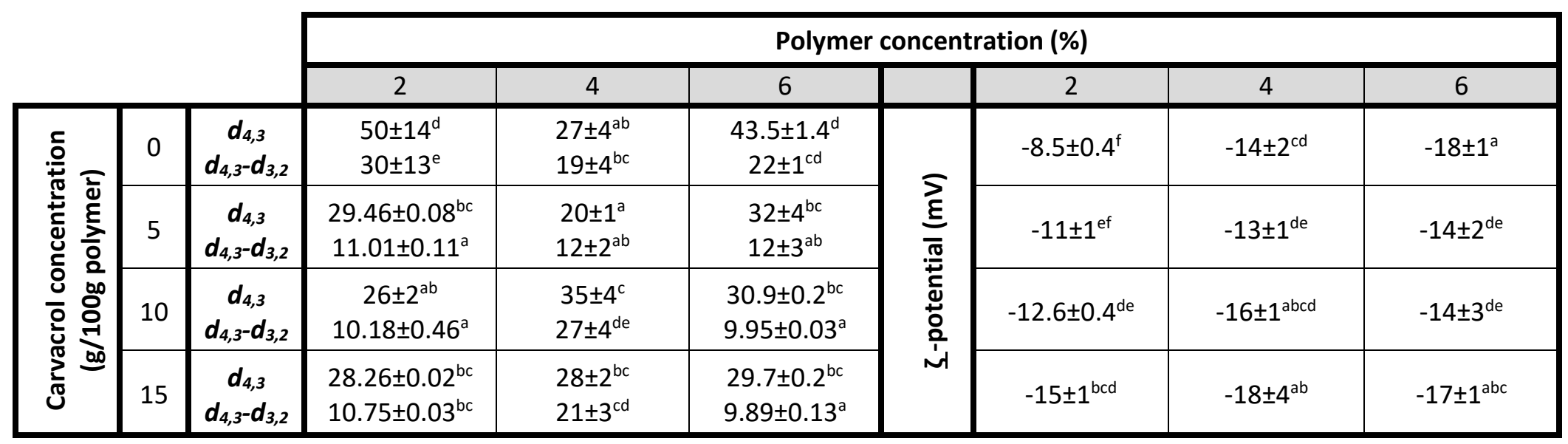

Different superscripts $(a, b, c .$.$) indicate, for the respective parameter, significant differences according to ANOVA test (p<0.05)$. 
Table 3: Physical properties for both polar and non-polar series: surface tension $(\gamma)$ and conductivity (א). Average values and standard deviations.

\begin{tabular}{|c|c|c|c|c|c|c|c|c|}
\hline & & \multicolumn{6}{|c|}{ Polymer concentration (\%) } \\
\hline & & & \multicolumn{3}{|c|}{ Polar system } & \multicolumn{3}{|c|}{ Non-polar system } \\
\hline & & & 2 & 4 & 6 & 5 & 10 & 15 \\
\hline \multirow{8}{*}{ 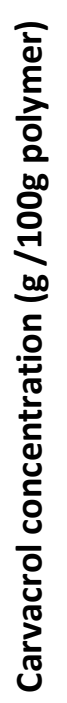 } & 0 & \multirow{4}{*}{$\frac{\widehat{\xi}}{\frac{\xi}{\xi}}$} & $54 \pm 1^{d}$ & $51 \pm 1^{c}$ & $48 \pm 1^{d}$ & $25.5 \pm 0.4^{\mathrm{a}}$ & $26.1 \pm 0.4^{\mathrm{bc}}$ & $26.5 \pm 0.2^{\mathrm{de}}$ \\
\hline & 5 & & $39 \pm 1^{a}$ & $39.7 \pm 0.4^{a}$ & $40 \pm 1^{c}$ & $25.3 \pm 0.3^{\mathrm{a}}$ & $26.2 \pm 0.4^{\mathrm{bcd}}$ & $26.3 \pm 0.2^{\mathrm{cd}}$ \\
\hline & 10 & & $42.2 \pm 0.3^{c}$ & $41 \pm 1^{b}$ & $31 \pm 1^{b}$ & $25.4 \pm 0.4^{\mathrm{a}}$ & $26.4 \pm 0.4^{c d}$ & $26.7 \pm 0.2^{\mathrm{e}}$ \\
\hline & 15 & & $40.5 \pm 0.1^{b}$ & $40.2 \pm 0.2^{b}$ & $30 \pm 1^{a}$ & $26.0 \pm 0.2^{b}$ & $26.3 \pm 0.2^{c d}$ & $26.9 \pm 0.2^{f}$ \\
\hline & 0 & \multirow{4}{*}{$\frac{\underset{\xi}{\frac{\xi}{v}}}{\frac{\tilde{y}}{\underline{y}}}$} & $133 \pm 2^{c}$ & $387 \pm 7^{i}$ & $321.1 \pm 0.3^{f}$ & $0.143 \pm 0.006^{b c}$ & $0.243 \pm 0.006^{f}$ & $0.123 \pm 0.006^{a}$ \\
\hline & 5 & & $124 \pm 1^{b}$ & $393 \pm 2^{i}$ & $291 \pm 3^{e}$ & $0.157 \pm 0.006^{c d}$ & $0.32 \pm 0.03^{g}$ & $0.117 \pm 0.006^{\mathrm{a}}$ \\
\hline & 10 & & $117 \pm 2^{\mathrm{a}}$ & $371 \pm 2^{h}$ & $288 \pm 3^{e}$ & $0.143 \pm 0.006^{\mathrm{bc}}$ & $0.16 \pm 0.02^{d}$ & $0.12 \pm 0^{\mathrm{a}}$ \\
\hline & 15 & & $112.3 \pm 0.4^{\mathrm{a}}$ & $345 \pm 9^{g}$ & $277 \pm 2^{d}$ & $0.203 \pm 0.006^{e}$ & $0.123 \pm 0.006^{a}$ & $0.127 \pm 0.006^{\mathrm{ab}}$ \\
\hline
\end{tabular}

Different superscripts $(a, b, c \ldots)$ within each series indicate, for the respective parameter, significant differences according to ANOVA test ( $p<0.05)$. 
Figure 1. Schematic diagram of the electrospinning setup used during the experiment.

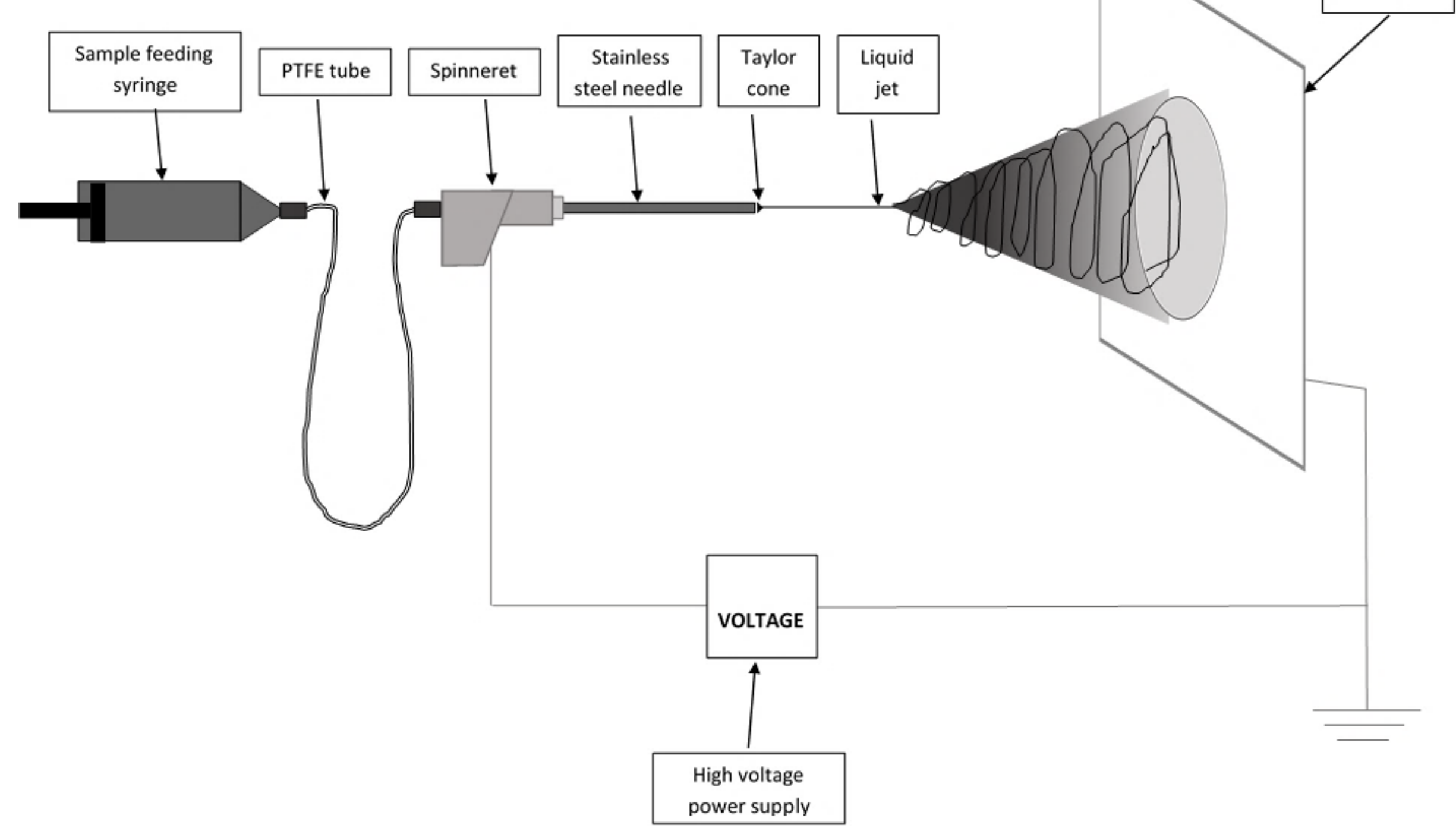


Figure 2. Particle size distribution in terms of volume for the polar systems with different polymer concentrations (a: $2 \%, b: 4 \%, c: 6 \%$ ) and carvacrol ratios.
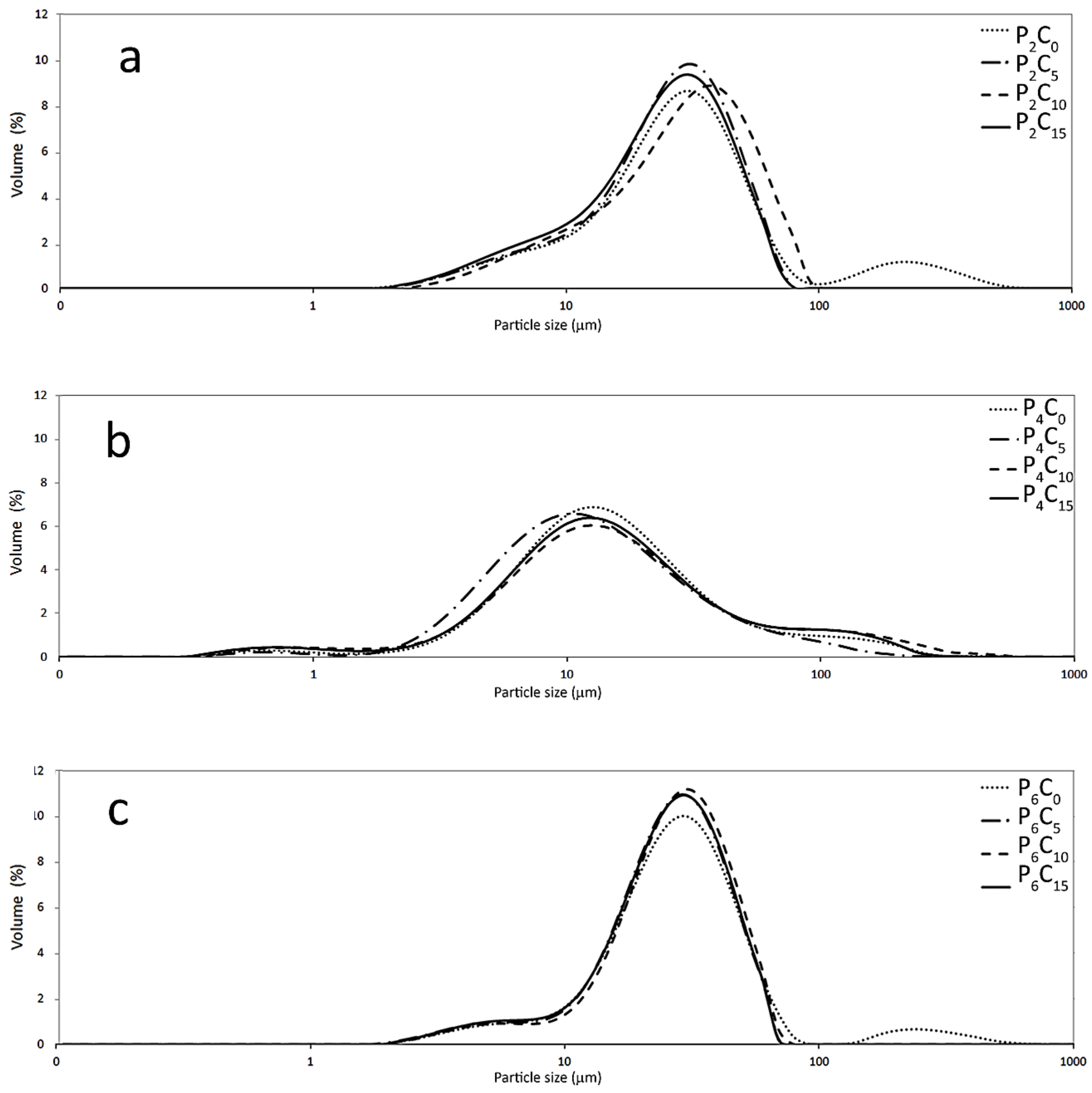
Figure 3. FESEM micrographs of nanostructure obtained for the electrospun material from polar matrices. Magnification factor between 2500x and 5100x.

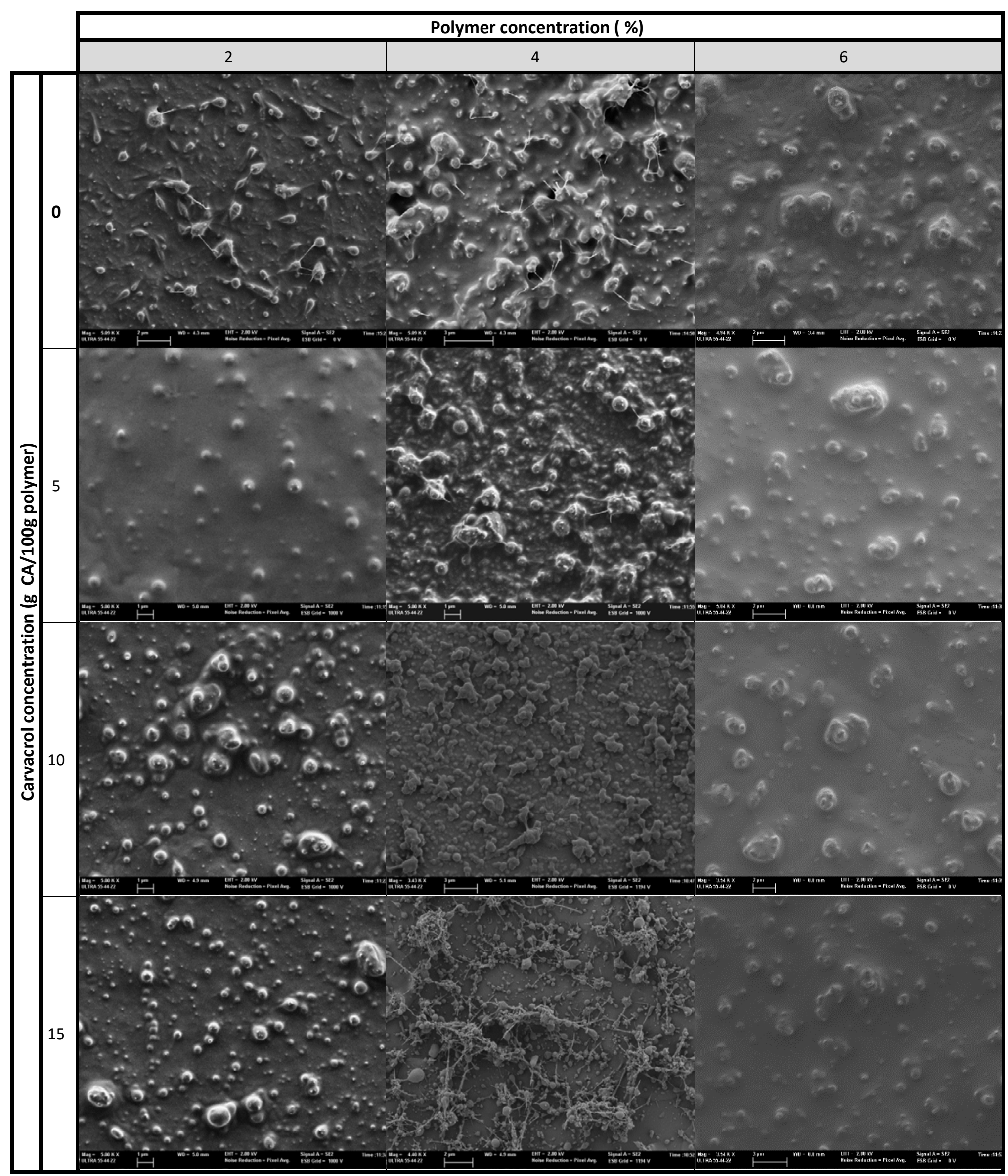


Figure 4. FESEM micrographs of nanostructure obtained for the electrospun material from non-polar matrices. Magnification factor of 2500x.

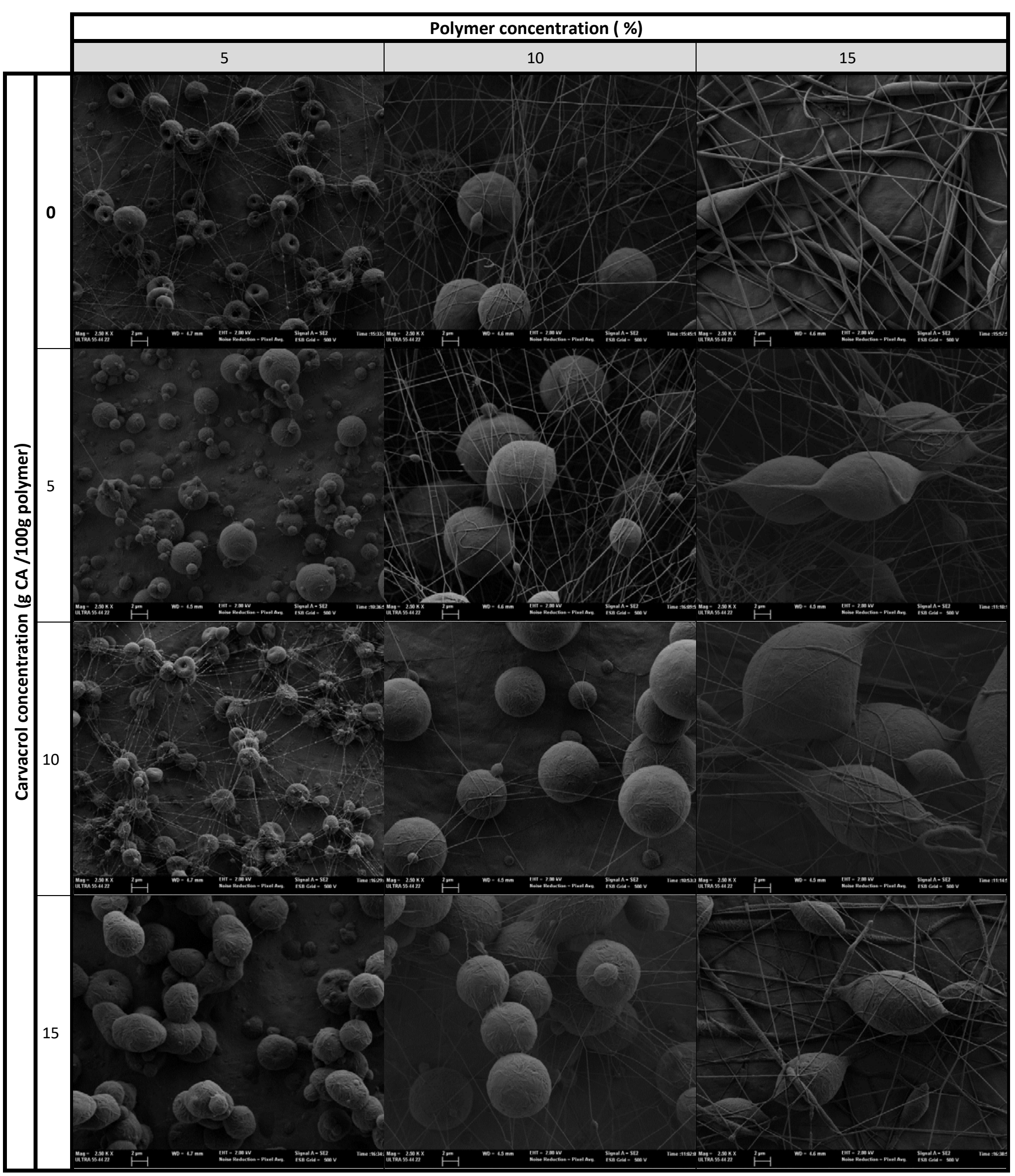


Figure 5. Encapsulation efficiency of carvacrol as a function of the polymer concentration in the liquid system, for polar and non-polar polymers with different carvacrol ratios. Mean values and standard deviations.

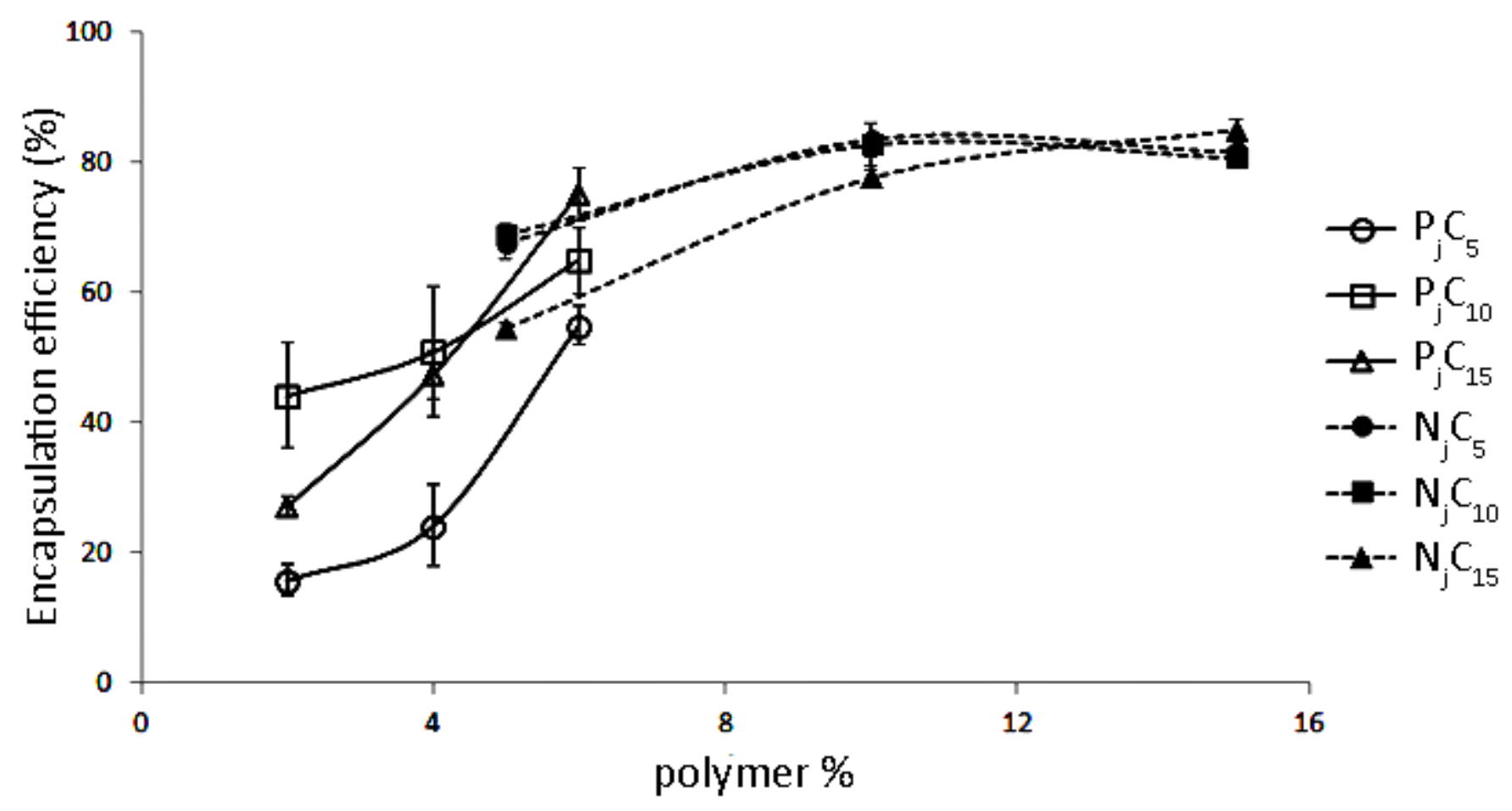

Figure 6. Carvacrol load of the polymer, expressed as $\mathrm{mg} \mathrm{CA} / \mathrm{g}$ of polymer, as a function of the polymer concentration, for polar and non-polar polymers with different carvacrol ratios. Mean values and standard deviations.

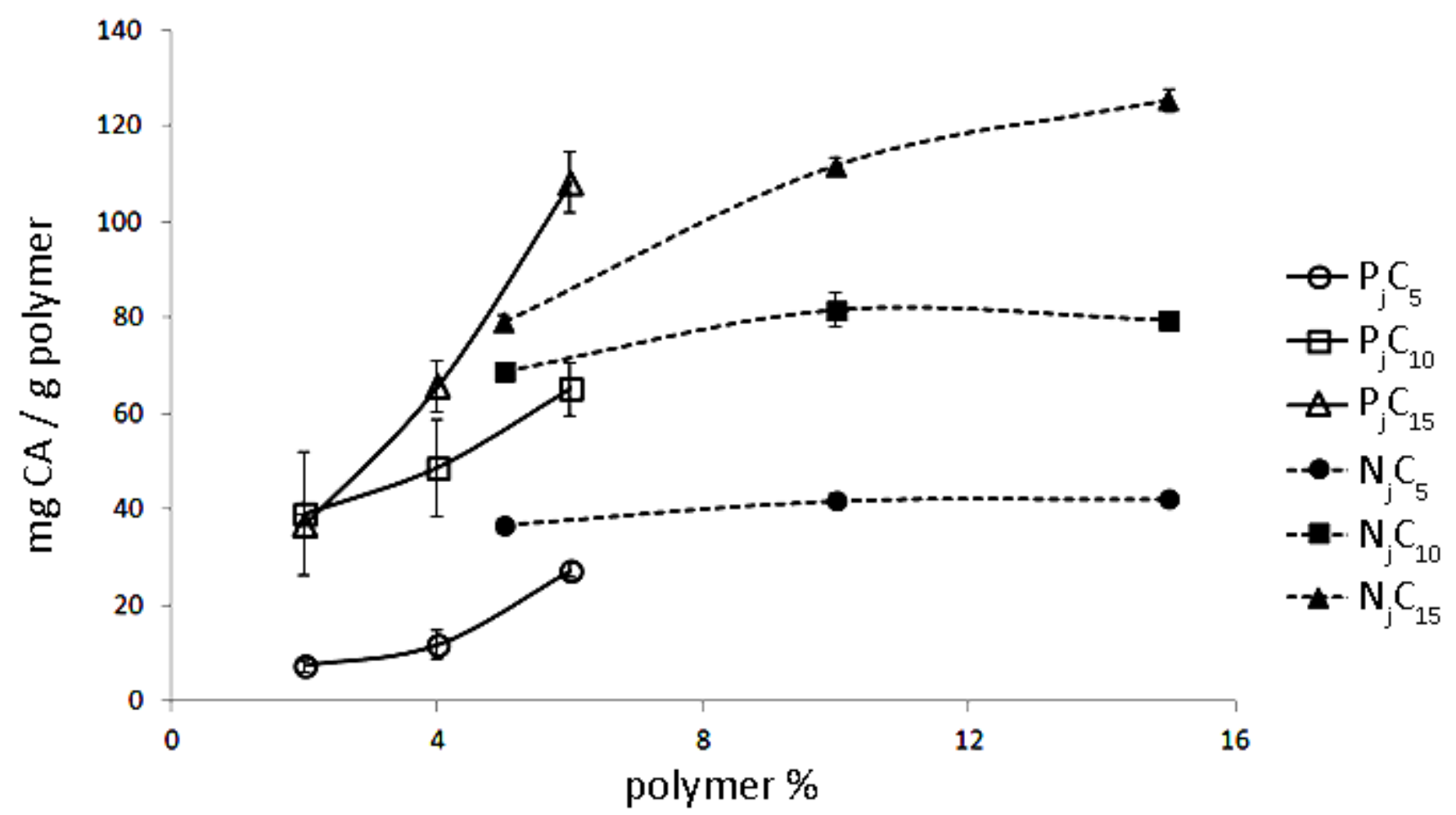

